\title{
Ankylosing Spondylitis with Bulbar Syndrome and Atlantoaxial Synovitis
}

LARISSA ANICETO MOREIRA, MD; RODRIGO BALBINO CHAVES AMORIM, MD; VITORIA EUGÊNIA GÓMEZ, MD, Serviço de Reumatologia, Universidade do Estado do Rio de Janeiro; CLARISSA CANELLA, MD, Clínica de Diagnóstico por Imagem, and Serviço de Radiologia e Diagnóstico por Imagem, Universidade Federal do Rio de Janeiro; ANA BEATRIZ BACCHIEGA, MD, Serviço de Reumatologia, Universidade do Estado do Rio de Janeiro; EDSON MARCHIORI, PhD, Serviço de Radiologia e Diagnóstico por Imagem, Universidade Federal do Rio de Janeiro, Rio de Janeiro, Brazil. Address correspondence to Dr. Clarissa Canella, Avenida Epitacio Pessoa 4476, bloco 02, apto 103, Lagoa CEP 22471-003.

E-mail: clacanella@yahoo.com.br. J Rheumatol 2014;41:2484-5; doi:10.3899/jrheum.140165

Ankylosing spondylitis (AS) is a chronic inflammatory disease. Neurological manifestations can occur because of atlantoaxial subluxation in about $14 \%$ of patients ${ }^{1}$.

A 43-year-old man diagnosed with AS according to the 1984 modified New York criteria presented with bulbar symptoms, such as severe dysphagia and dysphonia. Physical examination revealed the left hemitongue paralysis without any other focal neurological finding. He presented stiffness in the cervical, thoracic, and lumbar spine.

Magnetic resonance imaging (MRI) showed marked atlantoaxial synovitis with bilateral compression of the hypoglossal canal and jugular foramen, which explained the neurological involvement of the glossopharyngeal, vagus, and hypoglossal nerves. Sagittal T1-weighted MRI demonstrated severe synovitis in the atlantoaxial joint (Figure 1, white arrows). Axial T1-weighted images showed synovitis involving the hypoglossal canal bilaterally, which was more pronounced on the left side (Figure 2, white arrows).

The patient was initially treated with prednisone 1 $\mathrm{mg} / \mathrm{kg} /$ day and adalimumab $40 \mathrm{mg}$ every 14 days. After 2 weeks, prednisone was tapered off. There was an improvement on the baseline Bath Ankylosing Spondylitis Activity Index from 4.5 to 1.1 when assessed 12 weeks later. Symptoms such as dysphagia and dysphonia were resolved. Another MRI was performed demonstrating the regression of the synovitis. Because there was no atlantoaxial sublux-

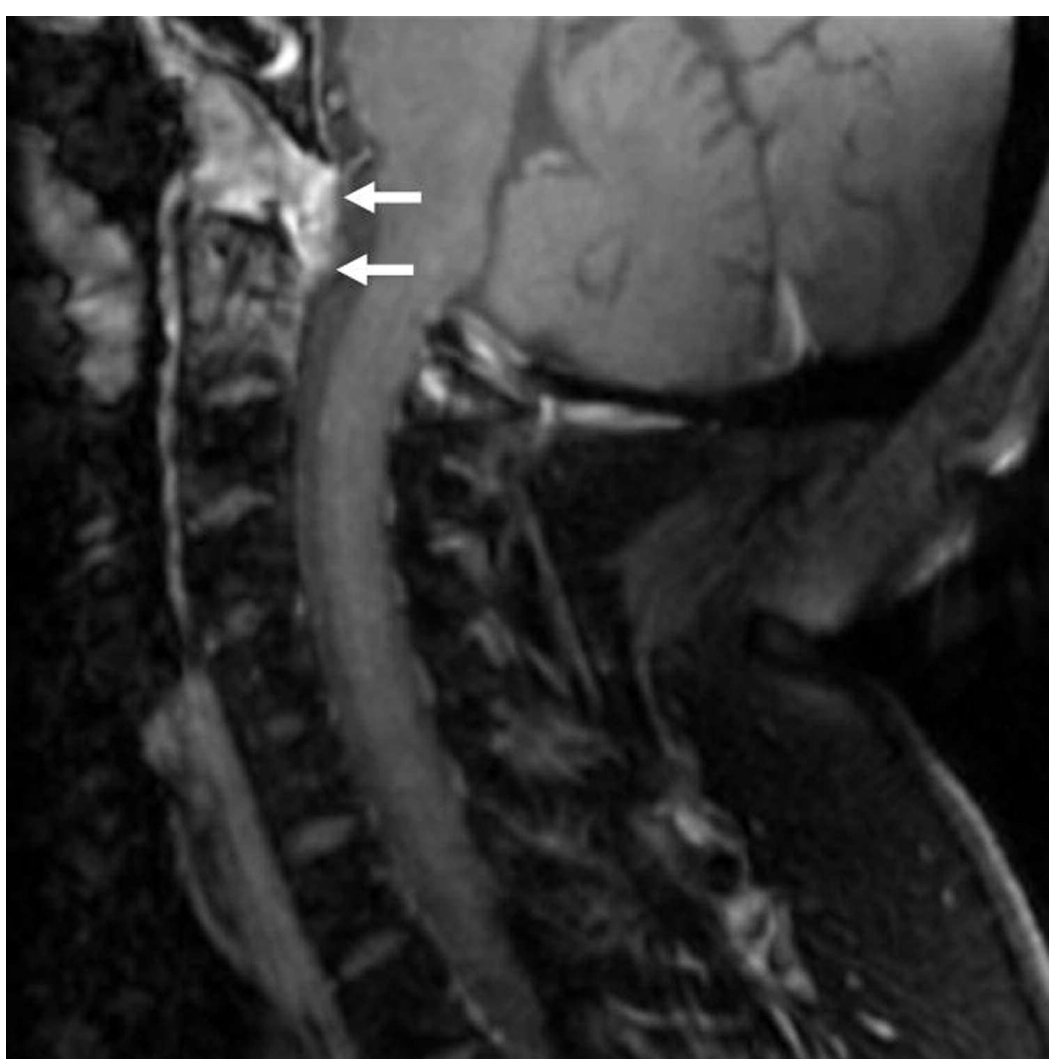

Figure 1. Sagittal T1-weighted MRI demonstrated severe synovitis in the atlantoaxial joint (white arrows). MRI: magnetic resonance imaging. 


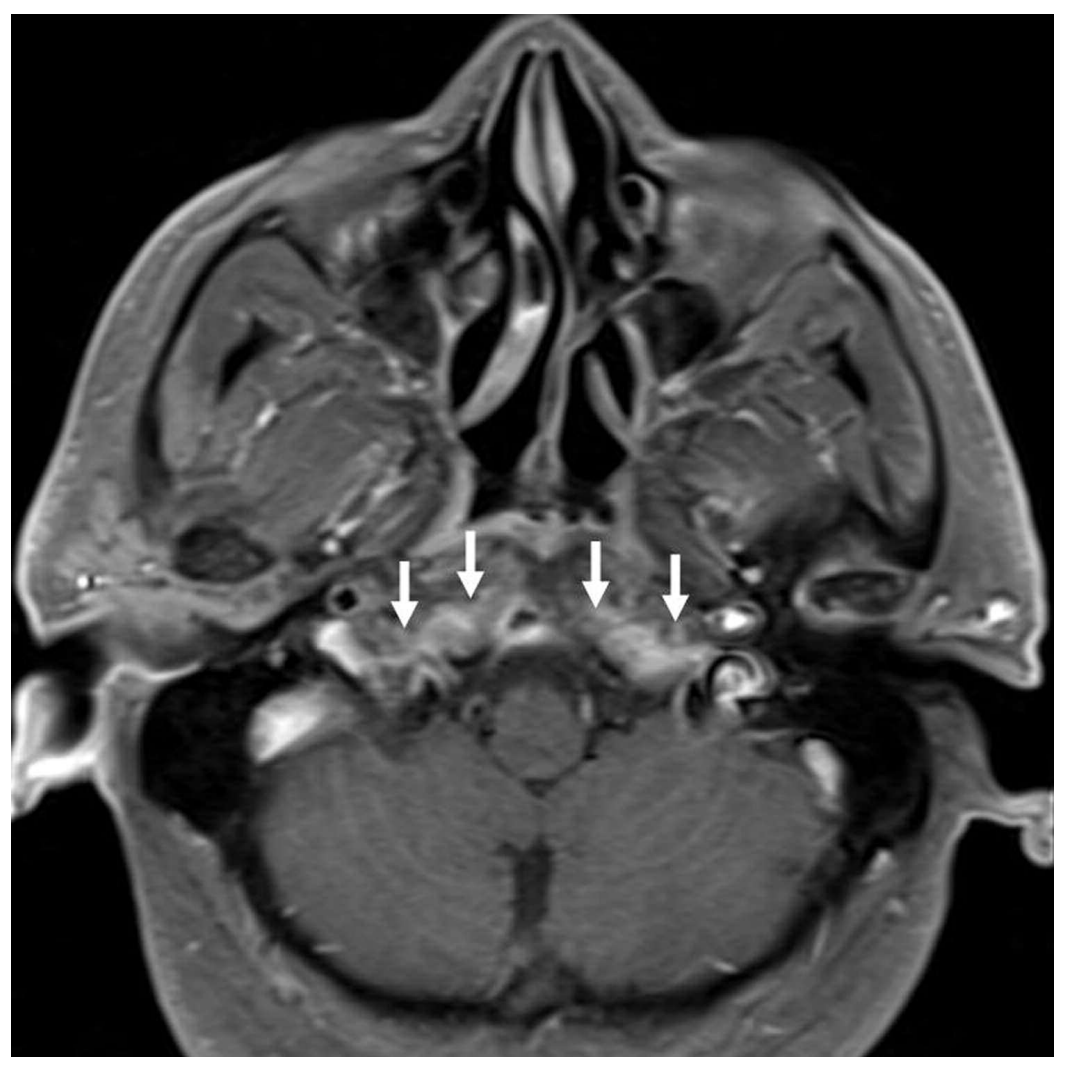

Figure 2. Axial T1-weighted images showed synovitis involving the hypoglossal canal bilaterally, which was more pronounced on the left side (white arrows).

ation and symptoms improved with immunosuppressive treatment, surgery was not performed.

AS is a chronic inflammatory disease that primarily affects the axial skeleton. Although neurological manifestations are uncommon, they can occur because of atlantoaxial subluxation in about $14 \%$ of patients ${ }^{1}$. The hypoglossal nerve could be involved in atlantoaxial disease in different ways. The most common is anterior subluxation, but vertical subluxation and even atlantoaxial rotatory dislocation may also occur ${ }^{2}$. A different kind of neurological involvement was described in this manuscript. The patient presented glossopharyngeal, vagus, and hypoglossal involvement because of synovitis without atlantoaxial subluxation.

Atlantoaxial synovitis in AS has rarely been reported in the literature ${ }^{3}$. We describe here neurological manifestations owing to severe atlantoaxial synovitis, involving the hypoglossal canal and jugular foramen, treated with immunosuppression.

\section{REFERENCES}

1. Lee JS, Lee S, Bang SY, Choi KS, Joo KB, Kim YB, et al. Prevalence and risk factors of anterior atlantoaxial subluxation in ankylosing spondylitis. J Rheumatol 2012;39:2321-6.

2. Chien JT, Chen IH, Lin KH. Atlantoaxial rotatory dislocation with hypoglossal nerve palsy in a patient with ankylosing spondylitis. J Bone Joint Surg Am 2005;87:1587-90.

3. Singh S, Balakrishnan C, Maheswari S. Pannus and enthesitis in the atlanto-axial region in ankylosing spondylitis. APLAR J Rheumatol $2005 ; 8: 138-40$. 